\title{
Role of cardiotocography in high risk pregnancy and its correlation with increase cesarean section rate
}

\author{
Manisha Gupta*, Punit Gupta
}

Department of Obstetrics and Gynecology, Jhalawar Medical College, Jhalawar, Rajasthan, India

Received: 22 October 2016

Accepted: 17 November 2016

\section{*Correspondence:}

Dr. Manisha Gupta,

E-mail: drmanisha1984@gmail.com

Copyright: ( ) the author(s), publisher and licensee Medip Academy. This is an open-access article distributed under the terms of the Creative Commons Attribution Non-Commercial License, which permits unrestricted non-commercial use, distribution, and reproduction in any medium, provided the original work is properly cited.

\section{ABSTRACT}

Background: FHR monitoring plays the most important role in management of labouring patient when incidence of fetal hypoxia and progressive asphyxia increases. Now a day's cardiotocography (CTG) become a popular method for monitoring of fetal wellbeing and it is assisting the obstetrician in making the decision on the mode of delivery to improve perinatal outcome. The aim of the study was to assess the effect of cardiotocography on perinatal outcome and its correlation with caesarean section rate.

Methods: In this prospective observational study 201 gravid women with high risk pregnancy in first stage of labour were taken. Result was assessed in the form of Apgar score at five minute, NICU admission, perinatal mortality and mode of delivery. Statistical analysis is done by using Chi square test and $\mathrm{p}<0.05$ is considered as statistically significant.

Results: Perinatal morbidity in the form of NICU admission is higher in nonreactive group as compare to reactive group $(75.7 \% \mathrm{v} / \mathrm{s} 22.8 \%)$. Cesarean section rate for fetal distress were higher in nonreactive group (87.8\%) in comparison to reactive group $(20.5 \%)$. So this study suggest that there is significant difference in mode of delivery with increasing chances of caesarean section in cases belong to non-reactive traces $(\mathrm{p}<0.001)$.

Conclusions: Admission test is non-invasive and the best screening test to evaluate the fetal health and to predict the perinatal outcome but it also associated with increase caesarean section rate.

Keywords: Admission test, Cardiotocography, Fetal distress, Perinatal outcome

\section{INTRODUCTION}

A larger part of the current preventive obstetrics practice consists of methods to detects, avoid and treat fetal asphyxia. In the last few decades, technological advances have undoubtedly contributed significantly to improve maternal and perinatal outcome. It is now possible to assess the fetus not only for structural malformations, but also for its physiological status and well-being. ${ }^{1}$ Assessment of fetal wellbeing in labour ward by admission cardiotocography helps us to look for already prevailing high risk factors and also new factors that have recently appeared. ${ }^{2-4}$ Cardiotocography (CTG) is a popular method for monitor fetal wellbeing and it help the obstetrician in making decision on the mode of delivery to improve perinatal outcome. Labour poses physiological stress over fetus by interrupting oxygenated blood supply in villous space. If fetus has baseline oxygen deficit, late and variable deceleration will be apparent. So cardiotocography is a good screening method to detect early fetal distress so timely intervention can be done to prevent perinatal morbidity and mortality.

The admission test first described by Ingemarsson et al is a short strip of fetal heart rate monitoring during labour. ${ }^{5}$ It is a dynamic screening test for the state of oxygenation of the fetus on admission of mother in labour room. Admission test is a natural contraction stress test that can 
assess the ability of fetus to withstand the functional stress of uterine contraction and helps to identify those cases at risk. It is 20 minute recording of FHR and uterine contraction using a CTG machine at the time of Admission to labour ward, so it is very simple, rapid and patient friendly procedure.

The aim of the study was to assess the effect of cardiotocography on perinatal outcome and its correlation with caesarean section rate.

\section{METHODS}

\section{Study design and setting}

This prospective study was conducted in the Department of Obstetrics and Gynaecology Sanjay Gandhi Memorial Hospital, Mangolpuri, New Delhi, from February 2013 to May 2014. A total of 201 high risk antenatal mothers were subjected to cardiotocography. Cardiotocography monitoring was performed on these mother and interpretations made based on fetal heart rate, base line variability, number of accelerations and deceleration and CTG was then designated as reactive or non-reactive. On this basis the fetal outcome was predicted by Apgar score, NICU admission and perinatal mortality. The prediction of cardiotocography traces with perinatal outcome and mode of delivery was done.

\section{Inclusion criteria}

Women who had Gestational age $\geq 36$ wks in first stage of labour with high risk factor like Anaemia, PIH, Diabetes mellitus, Rh Negative, PROM, IUGR (Intrauterine growth restriction, Post datism, Previous caesarean section, Bad obstetrics history, Oligohydramnios and decrease fetal movements.

\section{Exclusion criteria}

Patient excluded in this study group were gestational age $<36$ weeks and all antenatal patient without mentioned obstetric high risk factors in inclusion criteria.

\section{Methodology}

After obtaining the institutional ethical committee approval, study was started. Patients admitted in obstetrics unit with inclusion criteria, were analysed. Written informed consent was obtained. A detail clinical history of patient was taken. Period of gestation was ascertained by last menstrual period and the duration of previous menstrual cycles or by first trimester ultrasound scan if not sure of date. The Cardiotocography was done for $20 \mathrm{~min}$ and the rate of baseline variability, acceleration and deceleration were assessed according to RCOG criteria of CTG and here if any case of suspicious then CTG done >40 min and decision was taken either CTG reactive or Nonreactive. If CTG trace was nonreactive then iv fluid, left lateral position given to patients and repeat CTG taken for another $40 \mathrm{~min}$. If repeat CTG remain nonreactive then operative or instrumental intervention taken as soon as possible to decrease perinatal mortality and morbidity. ${ }^{6}$

\section{RESULTS}

Table 1: RCOG guidelines for use of electronic fetal monitoring. ${ }^{6}$

\begin{tabular}{|c|c|c|c|c|}
\hline Feature & Baseline (bpm) & Variability (bpm) & Decelerations & Accelerations \\
\hline Normal & $110-160$ & $\geq 5$ & None & Present \\
\hline Suspicious & $\begin{array}{l}100-109 \\
161-180\end{array}$ & $<5$ for $\geq 40 \leq 90 \mathrm{mins}$ & $\begin{array}{l}\text { Early deceleration, variable } \\
\text { decelerations, Single } \\
\text { prolonged deceleration for up } \\
\text { to } 3 \text { mins }\end{array}$ & \multirow[b]{2}{*}{$\begin{array}{l}\text { The absence of } \\
\text { accelerations } \\
\text { with otherwise } \\
\text { normal trace is of } \\
\text { uncertain } \\
\text { significance }\end{array}$} \\
\hline Pathological & $\begin{array}{l}<100 \\
>180 \text { Sinusoidal } \\
\text { pattern }>10 \text { mins }\end{array}$ & $<5$ for $>90 \mathrm{mins}$ & $\begin{array}{l}\text { Atypical variable } \\
\text { decelerations, Late } \\
\text { decelerations, Single } \\
\text { prolonged deceleration for } \\
\text { more than } 3 \text { minutes }\end{array}$ & \\
\hline
\end{tabular}

Table 2: Categorization of fetal heart rate traces.

\begin{tabular}{|ll|}
\hline Category & Definition \\
\hline Normal & A CTG where all four features fall into the reassuring category \\
\hline Suspicious & $\begin{array}{l}\text { A CTG where one of the features falls into 'non- reassuring category' and the remainder of the } \\
\text { features is reassuring. }\end{array}$ \\
\hline Pathological & $\begin{array}{l}\text { A CTG whose features fall into two or more non- reassuring categories or one or more } \\
\text { abnormal categories. }\end{array}$ \\
\hline
\end{tabular}


Table 3 shows that out of 201 studied high risk cases $63.2 \%$ had reactive CTG pattern and $36.8 \%$ had nonreactive CTG pattern.

Table 3: Distribution of studied cases according to reactivity of CTG.

\begin{tabular}{|lll|}
\hline CTG trace & Frequency & $\%$ \\
\hline Reactive & 127 & $63.2 \%$ \\
\hline Non-reactive & 74 & $36.8 \%$ \\
\hline Total & 201 & $100 \%$ \\
\hline
\end{tabular}

Table 4: Correlation of CTG with Apgar score at 5 minute.

\begin{tabular}{|c|c|c|c|c|c|}
\hline \multirow{2}{*}{$\begin{array}{l}\text { Apgar } \\
\text { at } 5 \\
\text { min }\end{array}$} & \multicolumn{2}{|c|}{ Reactive } & \multicolumn{3}{|c|}{ Non-reactive } \\
\hline & $\mathbf{F}$ & $\%$ & $\mathbf{F}$ & $\%$ & $\begin{array}{l}P \\
\text { value }\end{array}$ \\
\hline $0-4$ & 0 & $0.0 \%$ & 2 & $2.7 \%$ & $<0.001$ \\
\hline $5-7$ & 42 & $33.1 \%$ & 43 & $58.1 \%$ & \\
\hline$>7$ & 85 & $66.9 \%$ & 29 & $39.2 \%$ & \\
\hline Total & 127 & $100.0 \%$ & 74 & $100.0 \%$ & \\
\hline
\end{tabular}

In this studied group out of 74 non-reactive CTG $58.1 \%$ foetuses had Apgar score $<7$ and 39.2\% had Apgar score $>7$. So this study suggest that CTG had importance in detection of fetal distress with low Apgar score (P $<0.001)$ (Table 4).

This study suggest, foetuses with reactive CTG required less NICU admission as compared to non-reactive foetuses $(22.8 \% \mathrm{v} / \mathrm{s} 75.7 \%)$ with $\mathrm{p}$ value being significant $(\mathrm{P}<0.001)$ (Table 5).

Out of 74 non-reactive cases $65(87.8 \%)$ cases survived and $9(12.2 \%)$ cases died as compare to reactive group where all baby survived. So study suggests that there is strong correlation between CTG monitoring and decrease perinatal mortality. $(\mathrm{p}<0.001)$ (Table 6).

Table 5: Correlation between CTG reactivity and NICU admission.

\begin{tabular}{|c|c|c|c|c|c|}
\hline \multirow{2}{*}{$\begin{array}{l}\text { NICU } \\
\text { admission }\end{array}$} & \multicolumn{2}{|c|}{ Reactive } & \multicolumn{3}{|c|}{ Non-reactive } \\
\hline & $\mathbf{F}$ & $\%$ & $\mathbf{F}$ & $\%$ & $P$ value \\
\hline No & 98 & $77.2 \%$ & 18 & $24.3 \%$ & $<0.001$ \\
\hline Yes & 29 & $22.8 \%$ & 56 & $75.7 \%$ & \\
\hline Total & 127 & $100.0 \%$ & 74 & $100.0 \%$ & \\
\hline
\end{tabular}

Table 6: Correlation between CTG reactivity and perinatal mortality.

\begin{tabular}{|llllll|}
\cline { 1 - 5 } Perinatal & \multicolumn{2}{l}{ Reactive } & \multicolumn{2}{l}{ Non-reactive } & \\
\cline { 1 - 5 } mortality & F & $\%$ & F & \% & P value \\
\hline No & 127 & $100 \%$ & 65 & $87.8 \%$ & $<0.001$ \\
\cline { 1 - 5 } Yes & 0 & $0 \%$ & 9 & $12.2 \%$ & \\
\cline { 1 - 5 } Total & 127 & $100.0 \%$ & 74 & $100.0 \%$ & \\
\hline
\end{tabular}

Table 7: Sensitivity, Specificity, PPV and NPV of CTG for NICU admission.

\begin{tabular}{|ll|}
\hline Sensitivity & $75.7 \%$ \\
\hline Specificity & $77.2 \%$ \\
\hline PPV & $65.9 \%$ \\
\hline NPV & $84.5 \%$ \\
\hline
\end{tabular}

Table 7 shows that CTG monitoring had $75.7 \%$ sensitivity, $77.2 \%$ specificity with $65.9 \%$ positive predictive value.

Table 8 depicts the correlation between CTG reactivity and mode of delivery either by LSCS or vaginal delivery. $82.4 \%$ of non-reactive cases \& $20.5 \%$ of reactive cases had undergone LSCS.17.6\% of non-reactive CTG and $79.5 \%$ of reactive CTG traces cases had undergone vaginal delivery. So this study suggest that there is significant difference in mode of delivery with increasing chances of caesarean section in cases belong to nonreactive traces $(\mathrm{p}<0.001)$.

Table 8: Reactivity of CTG according to mode of delivery.

\begin{tabular}{|c|c|c|c|c|c|}
\hline \multirow[b]{2}{*}{$\begin{array}{l}\text { Mode of } \\
\text { delivery }\end{array}$} & \multicolumn{2}{|c|}{ Reactive } & \multicolumn{3}{|c|}{ Non-reactive } \\
\hline & $\mathbf{F}$ & $\%$ & $\mathbf{F}$ & $\%$ & $\begin{array}{l}P \\
\text { value }\end{array}$ \\
\hline $\begin{array}{l}\text { Vaginal } \\
\text { delivery }\end{array}$ & 101 & $79.5 \%$ & 13 & $17.6 \%$ & $<0.001$ \\
\hline $\begin{array}{l}\text { Caesarean } \\
\text { section }\end{array}$ & 26 & $20.5 \%$ & 61 & $82.4 \%$ & \\
\hline Total & 127 & $100.0 \%$ & 74 & $100.0 \%$ & \\
\hline
\end{tabular}

Table 9: Comparison of results on CTG monitoring in different study.

\begin{tabular}{|c|c|c|c|c|}
\hline Author & $\begin{array}{l}\text { Total } \\
\text { population }\end{array}$ & Subject & CTG & Benefit \\
\hline $\begin{array}{l}\text { FA } \\
\text { Manning } \\
\text { et al }^{9}\end{array}$ & 150 & $\begin{array}{l}\text { High } \\
\text { Risk }\end{array}$ & $\begin{array}{l}\mathrm{R}- \\
83 \% \\
\mathrm{Nr}- \\
17 \%\end{array}$ & No \\
\hline $\begin{array}{l}\text { Sundhu } \\
\text { GS et } \\
\mathrm{al}^{10}\end{array}$ & 150 & $\begin{array}{l}\text { High } \\
\text { Risk }\end{array}$ & $\begin{array}{l}\mathrm{R}- \\
67 \% \\
\mathrm{NR}- \\
33 \%\end{array}$ & Yes \\
\hline $\begin{array}{l}\text { Our } \\
\text { Present } \\
\text { study }\end{array}$ & 201 & $\begin{array}{l}\text { High } \\
\text { Risk }\end{array}$ & $\begin{array}{l}\mathrm{R}- \\
63.2 \% \\
\mathrm{NR}- \\
36.8 \%\end{array}$ & Yes \\
\hline
\end{tabular}

\section{DISCUSSION}

Cardiotocography (CTG) has become a popular method for monitor fetal wellbeing and it is assisting the obstetrician in making decision on the mode of delivery to improve perinatal outcome. 
Many studies have been undertaken to study the importance of CTG monitoring. Initial studies suggested, no role of CTG monitoring in good perinatal outcome, it only increases the rate of LSCS however other studies suggest that CTG monitoring has good role in improving perinatal outcome. A total 201 of high risk cases were chosen and subjected to the cardiotocography monitoring to find out the fetal wellbeing.

In our study out of 201 cases, $63.2 \%$ cases had reactive CTG and $36.8 \%$ had non-reactive CTG and most common indication for CTG monitoring were PIH 70 (34.8\%), previous LSCS 31(15.4\%), Oligohydramnios 28 (13.9\%), Postdatism 25 (12.4\%), Rh negative and IUGR $13(6.5 \%)$, GDM $11(5.5 \%)$ and Anemia 10 (5.0\%).

In study conducted by Sood et al Concluded that intrapartum CTG monitoring had reliable tool to detect pre-existing fetal distress and it increases operative intervention in high risk pregnancy. ${ }^{7}$ In study conducted by Verma et al Concluded that CTG monitoring can be used as screening test in detection and timely intervention in high risk foetuses. ${ }^{8}$

In our study out of 201cases, 87 cases underwent LSCS, $26(20.9 \%)$ had reactive and $61(82.4 \%)$ had non-reactive CTG. The study concludes that there is increased rate of caesarean section with use of CTG monitoring ( $p$ $<0.001$ ). So data of our study correlate with Sood and Verma study in having increased rate of caesarean section. In present study $63.2 \%$ cases has reactive CTG and $36.8 \%$ cases has non-reactive CTG and about similar result obtained in study conducted by Sundhu GS et al.

In our study increased rate of caesarean section may be attributed to the fact, that the type of population studied by us belonged to high risk group, while others studied general populations which includes both high risk and low risk cases. High risk group definitely not only had more chances of nonreactive CTG but also more chances of having increase rate of both maternal and fetal complication, if allowed to go to into normal vaginal delivery.

Thus, with all parameters and conclusions, CTG comes out as an important tool for intrapartum fetal surveillance. Though there is a definite increase in the rate of operative intervention, but relative fall in perinatal mortality rate, gives us immense satisfaction in timely saving the lives of many babies for which, an obstetrician strives and mother longs. Based on this study conducted by us, we suggest the use of CTG monitoring in high risk patients as a reliable tool in prediction of good perinatal outcome.

\section{CONCLUSION}

Admission test is noninvasive and the best screening test to evaluate the fetal health and to predict the perinatal outcome. So we can reduce the perinatal morbidity and mortality in our country. After CTG screening obstetrician should be able to assess that foetus is healthy and needful intervention can be taken.

It has therefore concluded that Admission test is a effective technique in detection and early prediction of pre-existing fetal distress and it is associated with increased cesarean section rate.

\section{Funding: No funding sources Conflict of interest: None declared \\ Ethical approval: The study was approved by the Institutional Ethics Committee}

\section{REFERENCES}

1. Shedd JWW. Appropriate technology in intrapartum fetal surveillance in progress in $\mathrm{O}$ and $\mathrm{G}$. Anilkumaran. S. Ingemarsson 1990; Edinburg, Churchill livingstone; p 127-140.

2. Admission CTG: A Rct Lancet. 2003;361(9356):46570.

3. Penning S, Garite TJ. Management of fetal distress. Obset Gynecol Clin North Am. 1999;26(2):259-74.

4. Zuspan FP. Predictor of intrapartum fetal distress: The role of electronic fetal monitoring. Am Journal Obset Gynecol. 1979;135:287-91.

5. Ingermarsson I, Arulkumaran S, Ingermarsson E, Tambyaraja RL, Ratnam SS. Admission test: A screening tet for fetal distress in labour. Obstet Gynecol. 1986;68:800-906.

6. Royal college of obstetricians and gynaecologists 2001 , the use of interpretation of cardiotocography in intrapartum fetal surveillance. Evidence based clinical guideline number 8 .

7. Sood AK. Evaluation of Non-stress test in high risk pregnancy. J Obstet Gynecol. 2002;52:71-5.

8. Verma A, Shrimali L. Impact of admission non-stress test as a screening procedure on perinatal outcome. IJMPS. 2012;3(5):06-10.

9. Manning FA, Harman CR, Morrison I, Menticoglou SM, Lange IR, Johnson JM. Fetal assessment based on fetal biophysical profile scoring. IV. An analysis of perinatal morbidity and mortality. Am J Obstet Gynecol. 1990;162(3):703-9.

10. Sundhu GS, Raju R, Bhattacharyya Col KK, Shaktivardhan. Admission cardiotography screening of high risk obstetric patient. Medical Journal Armed Forces India. 2008;64:43-5.

Cite this article as: Gupta M, Gupta P. Role of cardiotocography in high risk pregnancy and its correlation with increase cesarean section rate. Int $\mathbf{J}$ Reprod Contracept Obstet Gynecol 2017;6:168-71. 